\title{
FUNÇÃO, ESTRUTURA E INSTITUIÇÃO NA ANÁLISE JURÍDICA
}

\author{
FUNCTION, STRUCTURE AND INSTITUTIONS IN LEGAL ANALYSIS
}

\section{Lucas Fucci Amato*}

\begin{abstract}
Resumo:
Este artigo pretende analisar a proposta de Norberto Bobbio acerca de uma abordagem funcional do direito e discutir algumas alternativas a essa teoria. A abordagem funcional de Bobbio pretende-se complementar a um enfoque estrutural positivista, centrado na norma jurídica e no ordenamento jurídico. Propõe assim uma aproximação entre teoria do direito e sociologia jurídica. As alternativas discutidas, especialmente avançadas a partir de Niklas Luhmann e Roberto Mangabeira Unger, dão encaminhamentos diversos aos conceitos de estrutura, função e instituição, expandindo as fronteiras do método de análise jurídica esboçado por Bobbio, em direção a um construtivismo jurídico.

Palavras-chave: Abordagem funcional do direito. Estruturas jurídicas. Função do direito. Norberto Bobbio. Construtivismo jurídico.
\end{abstract}

\begin{abstract}
:
The paper aims at analyzing the Norberto Bobbio's proposal concerning a functional approach to Law and at discussing some alternatives to this theory. Bobbio's functional approach is made to be complementary to the positivistic structural approach, centered around the legal norm and the legal order. It proposes, therefore, a rapprochement between jurisprudence and sociology of law. The discussed alternatives, specially advanced starting with Niklas Luhmann and Roberto Mangabeira Unger, give different usages to the concepts of structure, function and institutions, expanding the boundaries of that method of legal analysis sketched by Bobbio, towards a legal constructivism.
\end{abstract}

Keywords: Functional approach to law. Legal structures. Function of law. Norberto Bobbio. Legal constructivism.

Introdução

O tema metodológico da análise funcional do direito, uma das maiores contribuições do pensador italiano Norberto Bobbio (1909-2004) à teoria jurídica da segunda metade do século XX, permite entrever as conexões entre as várias faces de seu pensamento. Concentrando-se neste ponto de sua teoria do direito, é possível ver como o tratamento do tema da função do direito por Bobbio tem como pressupostos as preocupações típicas de sua filosofia jurídica e política.

* Bacharel em Direito e Doutor em Filosofia e Teoria Geral do Direito pela USP, com estágio doutoral como
visiting researcher na Harvard Law School. Contato: lucasfamato@gmail.com. 
$\mathrm{Na}$ teoria do direito, Bobbio permaneceu como um expoente do positivismo jurídico, seguidor de Kelsen, mas com grande sensibilidade sociológica. Isso lhe permitiu ensaiar sínteses como aquela operada entre o par kelseniano norma jurídica/ordem jurídica (ou nomoestática/nomodinâmica) e uma teoria pioneira de nítida inspiração sociológica como a teoria do ordenamento jurídico de Santi Romano, que contrastava não apenas com o monismo de Kelsen (ao defender uma postura de pluralismo jurídico), mas também com seu normativismo (em Romano o direito não é definido a partir da norma, mas sim da instituição, não simplesmente enquanto pessoa jurídica, mas como uma unidade de direito objetivo). ${ }^{1} \mathrm{O}$ mesmo perfil é evidenciado quando Bobbio defende a complementaridade entre o ponto de vista positivista de inspiração kelseniana (preocupado com a estrutura do direito) e um ponto de vista sociológico que ele (Bobbio) intenta trazer à teoria do direito: a perspectiva da análise da função do direito. Esse intento foi consagrado em sua coletânea Da estrutura à função, publicada em 1977, com textos originalmente veiculados entre 1969 e 1976.

Mas, além de revelar um teórico do direito com sensibilidade sociológica, o tema da análise funcional do direito, que emerge em sua produção no final dos anos de 1960 e início da década seguinte, vincula-se à sua transição da filosofia do direito à filosofia política (em 1972 Bobbio deixa de ser professor da primeira e passa à segunda matéria). Isso porque o tema da função do direito (re)emerge na década de 1970, sobretudo para sociólogos, quando se trata de pensar as mudanças do direito moderno na passagem de um modelo liberal oitocentista ao contexto do Estado social da metade do século XX. Na filosofia política de Bobbio, um tema chave é a distinção entre Estado e sociedade civil, reconstruída desde o jusracionalismo moderno até Hegel, Marx e Gramsci (BOBBIO, 2010b; 1999; 1982; BOBBIO; BOVERO, 1991). Pois bem, a distinção entre Estado e sociedade civil não apenas é o correlato da "grande dicotomia" entre direito público e privado (BOBBIO, 2007, p. 139-158) como também apresenta os pares pelos quais são descritos tanto o Estado liberal quanto o Estado social. No primeiro, o direito aparece como instrumento de limitação do Estado diante da sociedade - ao Estado policial corresponde um direito repressivo, com uma função de garantia e sanções quase que exclusivamente negativas. No Estado social, aparece uma "função promocional" do

\footnotetext{
A síntese entre Kelsen e Romano operada por Bobbio é evidenciada sobretudo no primeiro capítulo da sua Teoria da norma jurídica (quando trata de norma, instituição e pluralismo jurídico) e no último capítulo de sua Teoria do ordenamento jurídico (BOBBIO, 2010a, p. 19-24, 313-333). A distinção entre estática jurídica (que Bobbio explicará como teoria da norma) e dinâmica jurídica (que Bobbio denomina de teoria do ordenamento jurídico) está presente nos capítulos 4 e 5 de Kelsen (2006). Santi Romano (2008, p. 89) conceitua instituição como "um ordenamento jurídico, uma esfera em si mesma, mais ou menos completa, de direito objetivo". Bobbio (2007, p. 159-180) defende a independência da teoria do direito como instituição (em oposição à definição do direito pela norma jurídica) em relação à teoria do pluralismo jurídico em Romano.
} 
direito e cresce a relevância das sanções positivas. Vê-se assim como o positivista de sensibilidade sociológica alia-se ao filósofo político de posição "social-liberal" - esta conexão ajuda a explicar como Bobbio chega à proposição de uma análise funcional do direito. $^{2}$

Para desvendar a novidade dessa proposta em termos de teoria do direito, vale situá-la em contraste com a descrição estrutural do direito, a que dedicamos o tópico a seguir. Partindo de uma teoria estrutural do direito (que terá como ápice a ideia de ordenamento jurídico) é que Bobbio chegará à elaboração complementar de uma teoria funcional, que analisaremos em um segundo momento deste artigo. O terceiro passo é apresentar alternativas às concepções bobbianas tanto da estrutura quanto da função do direito. Cumprimos essa etapa sugerindo um contraponto entre dois autores que elaboraram uma ampla teoria da sociedade e do direito - o alemão Niklas Luhmann (1927-1998) e o brasileiro Roberto Mangabeira Unger (n. 1947) - e o fizeram logo em seguida a Bobbio, sobretudo desde o final dos anos 1960 até a década de 90 (no caso de Luhmann) e dos anos 1970 até hoje (no caso de Unger). A visão dos conceitos de função, estrutura e instituição como pontos fulcrais de uma teoria do direito é o que está em jogo nessa comparação e assim informa nova proposta, construtivista, de análise jurídica.

\section{A descrição estrutural do Direito}

Com raízes nas tradições formalistas do século XIX (como a jurisprudência dos conceitos), mas com uma completa refundação epistemológica na Teoria pura do direito de Kelsen, a análise formal ou estrutural do direito dominou a estruturação tanto da teoria do direito (com pretensão de ciência) quanto de uma dogmática voltada à aplicação judicial e ao estudo dos ramos específicos do direito. Bobbio tem consciência de que a cisão entre o jurista dogmático e o cientista social empirista tem raízes históricas definidas, mas que seu aprofundamento contribui antes para o amesquinhamento de ambos os lados do que para a profundidade analítica e precisão conceitual. A tarefa de um pensamento jurídico renovado é antes superar tal abismo - embora seja improvável o desaparecimento tanto de uma dogmática voltada ao problema relativamente restrito, mas de todo o modo não irrelevante, da interpretação e aplicação jurisdicional do direito, quanto de uma ciência social positiva voltada à quantificação empírica com base em teorias de médio alcance. Apenas uma sensibilidade sociológica inserta na racionalidade formalista do jurista pode dar conta de problemas jurídicos como aqueles emergentes à época em que Bobbio escreve, como um crescimento ou reconhecimento de uma heterogeneidade de fontes e

2 É similar e contemporâneo ao esforço teórico de Bobbio o estudo que aponta os tipos de direito "repressivo", "autônomo" e "responsivo", encontrado em Nonet e Selznick (2001), originalmente publicado em 1978. 
centros de produção do direito (ao lado da lei estatal, o contrato coletivo e o costume, como produção espontânea de comunidades específicas). Ao jurista, a sociologia (ou as ciências sociais de modo geral, como a ciência política, a economia, a administração) pode oferecer um ganho cognitivo para suas tarefas de identificação, interpretação, ordenação e mesmo proposição de regras. De outro lado, às ciências sociais desde seus primórdios o direito legou um vocabulário compartilhado de intensa qualidade descritiva - conceitos tais como os de tipo, papel, sanção, expectativa, status e institucionalização foram retrabalhados na sociologia a partir de um material de origem jurídica (BOBBIO, 2007, p. 33-51). É sob tal luz de uma compreensão interdisciplinar, voltada aos ganhos que a teoria social pode oferecer à teoria jurídica e vice-versa, que Bobbio enfatiza a complementaridade das perspectivas estrutural e funcional sobre o direito. A novidade de Bobbio está justamente em reconhecer a diferença e complementaridade entre as perspectivas, mas principalmente em elevar a perspectiva funcional a uma dimensão relevante da teoria do direito, até então preocupada apenas com o meio, em uma visão instrumental e formalista do direito (presente tanto em Jhering quanto em Weber). ${ }^{3}$ Afinal, análises funcionais já eram e são recorrentes na sociologia e antropologia jurídicas. A questão é que muitas vezes foram desprezadas do ponto de vista da "ciência do direito" dominante.

Assim, por exemplo, os sociólogos funcionalistas de inspiração marxista viam como função do direito a generalização dos interesses particulares da classe dominante - uma forma de ideologia, de superestrutura destinada a reforçar a conservação de determinado modo de produção (BOBBIO, 2007, p. 84). De outro lado, Luhmann representa uma sociologia funcionalista que dá especial relevo ao direito, ao contrário de seu mentor teórico, Parsons. Para Luhmann, o direito não pode ser definido de forma estrutural, pois se espraia por toda a sociedade - as expectativas são as estruturas sociais. A especificidade do direito, então, só pode ser captada em relação à sociedade daí a definição do direito por sua função, de generalização congruente de expectativas normativas (LUHMANN, 2004, p. 148). Já na antropologia jurídica, o funcionalismo foi representado por autores como Radcliffe-Brown (1973, p. 232-269), que nos anos 50 concebia a "função" como elemento de interconexão entre a "estrutura" (o ajuste ordenado das partes de um todo) e o "processo" (a dinâmica de ordenação, de produção da estrutura).

3 Bobbio (2007, p. 86-87) destaca que mesmo a importante obra de Jhering A finalidade no direito tratava sobretudo do direito como instrumento, como organização e coação. Weber, com sua tese da progressiva racionalização formal do direito moderno, também foca o direito como meio disponível a fins variados. Weber, assim, não assume a postura "material" típica da sociologia jurídica, mas sim uma postura "formal", próxima da kelseniana (AMATO, 2015, p. 230 e 236). 
Antes dos enfoques mencionados, porém, duas abordagens funcionalistas pioneiras no campo jurídico merecem registro. De um lado, contribuição notável à análise jurídica foi dada pelo estudo de Karl Renner sobre as instituições de direito privado. Em livro de 1929 que desenvolvia temática que o autor já vinha trabalhando desde o início do século, Renner (1949, p. 271) defendia que "nem a substância jurídica nem o conteúdo normativo da instituição jurídica individual, nem o efeito combinado de suas instituições complementares revela completamente sua função social", a qual só poderia ser entendida contextual e historicamente, especialmente - no caso dos institutos de direito privado com referência à economia.

De outro lado, Felix Cohen (1935), representante do realismo jurídico americano, já havia apresentado uma espécie de crítica funcional e pragmática ao formalismo logicista dos práticos do direito. Coisificando palavras como propriedade e devido processo legal, a prática judicial sofreria de uma espécie de alienação, negando-se a reconhecer-se como produtora ela mesma do sentido dos conceitos jurídicos e deixando de admitir que tais conceitos são apenas ferramentas de linguagem, memória e raciocínio, meros instrumentos para a consideração de argumentos de fundo ético e para a avaliação de evidências empíricas. A crítica funcional diz respeito aqui ao caráter circular e tautológico dos raciocínios judiciais, que pretendiam considerar apenas uma relação lógica e dedutiva entre conceitos doutrinários e máximas de tradição, excluindo de seu horizonte os fatos e razões sociais, as justificativas morais, econômicas ou políticas envolvidas na matéria sob julgamento, bem como os efeitos sociais, políticos, econômicos que a decisão judicial neste ou naquele sentido poderia produzir. Uma abordagem funcional do direito, ao contrário, volta-se a erradicar conceitos que não podem ser traduzidos em termos de experiência verificável (mas por meio dos quais se costuma decidir, com consequências concretas) e a dispensar controvérsias sem sentido; em termos positivos, a visão funcional procura redefinir conceitos contextualmente, iluminando os fatos mal traduzidos em ficções conceituais e redefinindo-os em termos de suas implicações e consequências.

Mas, diante da diversidade de funcionalismos, em que consiste especificamente a análise funcional de Bobbio? A tese de Bobbio (2007, p. XII) é de que a passagem do Estado liberal, policial, garantista para o Estado social, provedor, dirigista metamorfoseia o direito, que deixa de ser apenas um instrumento de controle social, passando progressivamente a abarcar com uma ênfase inédita uma função de direção social - a chamada "função promocional" do direito. Ao lado de multas, indenizações, reparações, ressarcimentos, de uma atuação protetora e repressiva, o direito passa a oferecer meios de indução e incentivo a condutas que se quer promover.

A busca da definição do direito na tradição positivista ofereceu vários pontos de partida e opções de conceituação. Em sua Teoria do ordenamento jurídico, Bobbio (2010a, p. 185-200) ressaltara como a ideia de ordenamento jurídico era um pressuposto 
necessário da teoria da norma jurídica, pois a delimitação do campo jurídico dependeria sobretudo dos postulados associados à ideia de ordenamento: unidade, coerência e completude. Não apenas para fins práticos e dogmáticos associados à aplicação do direito, esses axiomas apresentam-se como relevantes na visão positivista uma vez que não é possível a priori diferenciar uma norma jurídica de outras normas sociais - a relação de validação formal conforma a estrutura escalonada do ordenamento que confere a uma norma o status de norma jurídica.

De modo similar, Hart (2007, p. 89-135) definiria o direito como um "sistema de regras primárias e secundárias", colocando no fechamento desse sistema uma regra social - o fato de os oficiais que aplicam o direito (sobretudo juízes) reconhecerem certas fontes formais do direito, delimitando assim o campo das regras jurídicas. Bobbio (2007, p. 53-54) nota como Hart oferece uma definição estrutural do direito - pela ideia de sistema de regras -, mas sua definição do conceito de direito ("o que o direito é") tem como pano de fundo uma explicação de raiz funcionalista: embora não esclareça propriamente "para que o direito serve" (problema típico da análise sociológica da função do direito em relação à sociedade), Hart constrói a hipótese de que as regras secundárias apareceram como solução a necessidades funcionais do direito (as necessidades de certeza, mudança e eficácia, às quais respondem as regras secundárias de reconhecimento, alteração e julgamento).

Vale aqui o contraste entre Hart e Kelsen. O primeiro buscava compreender o direito de um ponto de vista "externo moderado" (HART, 2007, p. 98-101) e era um jurista com inspirações na sociologia compreensiva de Weber e na filosofia da linguagem que marca a tradição analítica britânica. O conceito de direito é definido tanto como "um ensaio sobre teoria jurídica analítica" quanto como "um ensaio de sociologia descritiva" (HART, 2007, p. 1). Já Kelsen era preocupado sobretudo com a distinção metodológica entre a análise sociológica e a análise jurídica (KELSEN, 2000a, p. 57-63; FEBBRAJO, 2010, p. 1-85). De um lado, ser, necessidade, natureza, causalidade. De outro, dever ser, liberdade, cultura, imputação. O direito, como "ciência do espírito", ocupa-se das relações normativas entre fato e norma apenas na medida em que a norma imputa a um fato uma sanção, gerando como dever a conduta de evitar a sanção. Para reconhecer uma norma como jurídica, é preciso encontrar seu fundamento formal de validade em outra norma, desvelando a estrutura da ordem jurídica (KELSEN, 2006, p. 1-65; BOBBIO, 2008, p. 55-87). Kelsen era sobretudo preocupado com a neutralidade axiológica de uma visão científica do direito, associada a seu pensamento político de defesa de um relativismo ético (KELSEN, 2000b; BOBBIO, 2007, p. 188-210). Em uma concepção instrumental do direito, este aparece como uma técnica a serviço de variados fins (BOBBIO, 2007, p. 56-64). Daí que a diferença entre a ordem estatal e a de um bando de salteadores seja meramente a eficácia global da ordem jurídica em dado território - reconhecendo a ordem 
mais eficaz, o intérprete pressupõe uma norma fundamental para construir a relação ideal de validade, fundada na ideia de um escalonamento formal de normas em relação de supra e infraordenação (KELSEN, 2006, p. 48-55; MICHELON JR., 2004, p. 92-113). A validade, como juízo puramente jurídico, evita ao máximo a intrusão de juízos políticos sobre valores ou avaliações empíricas sobre a eficácia (tema que é deixado à sociologia). Do ponto de vista jurídico, o direito existe por si mesmo ao regular a própria produção de normas jurídicas. A validade é o modo de existência próprio do direito - ela basta para a ciência jurídica (DE GIORGI, 1998, p. 80-94).

É de se notar que a conceituação do direito a partir de uma relação sistemática ou ordenada de validação entre normas concorreu com uma tradição ainda mais enraizada de conceituação do direito a partir da noção de obrigação - e das noções correlatas de sanção e coação. Essa concepção, que marca inclusive a Teoria pura do direito quando Kelsen (2006, p. 33-65) define o direito como "ordem social coativa", foi objeto da crítica de Hart (2007, p. 23-31 e 59-87), quando afasta a teoria imperativista do direito, típica do positivismo de John Austin, que reconhecia como jurídicos os comandos emanados por aquele a quem todos obedecem - o soberano. Em oposição a isso, Hart buscaria também uma concepção estrutural do direito - definindo-o como um sistema de regras. Surpreende, porém, que Bobbio retome a tradição da conceituação do direito a partir do tripé obrigação-sanção-coação, criticando-a de um ponto de vista não mais estrutural, mas propriamente funcional. Assim, Bobbio (2007, p. 1-5) nota a vinculação de tal construção teórica a um direito de funções protetoras e repressivas, como técnica de controle social a serviço de um Estado liberal, focado quase exclusivamente em policiar os atos ilícitos (e não em promover ou induzir condutas positivas). O que subjaz a tal função repressiva e protetora do direito é a imagem do contrato social, com a constituição do estado civil como uma situação em que o direito é usado para limitar o Estado diante do cidadão e desenhar as esferas de liberdade de cada um nas relações privadas, preservando a ordem pública.

Análise estrutural e análise funcional

Bobbio enfatiza a insuficiência de uma análise apenas estrutural do direito, mas se nega a rejeitá-la em favor de uma análise puramente funcional. Assume que o direito é uma técnica de organização social que serve a variados fins, como já concebia Kelsen (2000c, p. 21-41). Quando se reconhece que o direito pode desempenhar funcionalidades diversas (repressão, prevenção, indução, promoção), esse entendimento apenas é reforçado. O que se desfaz é a crença de que o direito atua apenas pela ameaça de punição, pois, ao lado do poder coativo, o Estado pode atuar de modo juridicamente relevante pelo poder econômico, estimulando e premiando condutas. O modo de colocar 
em movimento a máquina jurídica não invalida a visão estrutural do ordenamento jurídico; apenas a complementa por sua outra face: a análise funcional (BOBBIO, 2007, p. 77-78). Quanto à estrutura, diz Bobbio (2007, p. 209), Kelsen "permanece perfeitamente de pé, mesmo depois dos desenvolvimentos mais recentes da análise funcional".

A diferença entre estrutura e função só aparece claramente no momento em que é possível perceber como uma mesma estrutura (as normas e o ordenamento jurídico) é capaz de servir a diferentes propósitos (como já indicara Renner). Assim, apenas a mudança funcional do direito, na passagem do Estado liberal ao social, ilumina a importância de um estudo da função, em paralelo à análise formal ou estrutural do direito. Bobbio (2007, p. 113) esforça-se para frisar que não existe uma relação biunívoca entre estrutura e função: uma mesma estrutura pode servir a diferentes funções. Do ponto de vista estrutural, seja quanto a normas primárias (de conduta), seja quanto a normas secundárias (de organização), é possível trabalhar com funções repressivas, protetivas ou, de outro lado, promocionais e indutivas. Por isso, Bobbio critica a concepção dominante (kelseniana, inclusive) de ordenamento jurídico como ordem coativa, notando como a própria linguagem jurídica tem dificuldades em reconhecer a diferença de funções associáveis a uma mesma estrutura: afinal, se para a sociologia é clara a diferença entre sanções positivas e negativas, no direito foi admitida quase que exclusivamente a norma com a imputação da ameaça do castigo - sanção para o direito é pena, indenização, restituição, ou seja, sanção negativa (BOBBIO, 2007, p. 7-10 e 23-24).

Segundo entende Bobbio, o conceito de função e a análise funcional oferecem uma perspectiva axiologicamente neutra, seguindo os ditames das ciências sociais que se manifestam, por exemplo, em Weber, Kelsen ou Hart (BOBBIO, 2008, p. 215-240). São o oposto de uma visão finalística, fundada em uma concepção teleológica da ordem natural, segundo a qual cada ente tenderia a um estado ótimo - seu fim (HART, 2007, p. 205).

Para realçar a mudança funcional do direito na passagem ao Estado social isto é, as funcionalidades que o direito adiciona neste tipo de configuração social -, Bobbio apresenta um quadro complexo de relações entre normas positivas e negativas e sanções positivas e negativas. Normas positivas impõem uma conduta, são comandos de dar ou fazer. Podem ser reforçadas por sanções positivas ou negativas, isto é, pela promessa de prêmios ou castigos. Já normas negativas são proibições - tanto se pode prometer vantagens pela omissão da conduta indevida quanto se pode imputar uma punição, uma sanção negativa. No Estado social o estímulo a fazer ou desestímulo a não fazer estão vinculados, sobretudo, às sanções positivas, premiais, ligadas a comandos ou proibições (BOBBIO, 2007, p. 6).

As sanções negativas (ameaça de punição) e as sanções positivas (promessa de vantagem) podem ser tanto atributivas (de um mal ou de um bem, respectivamente) 
quanto privativas (de um bem ou de um mal, respectivamente). O castigo pode ser a imposição de uma multa, de uma indenização, de uma privação da liberdade, de uma perda de capacidade civil. A sanção negativa funciona por retribuição ou reparação (ressarcimento). Já a sanção positiva, o prêmio é, sobretudo no Estado social, uma técnica de estímulo por meio de compensações, de indenizações que visam a retribuir o bem ou valor que o indivíduo tenha gerado para a sociedade (BOBBIO, 2007, p. 24-26). Mas como conceber a sanção promocional como sanção jurídica, isto é, como sanção institucionalizada, regulada por normas e garantida por um aparato repressivo (o Estado como monopólio do exercício da violência legítima)? ${ }^{4}$ A resposta de Bobbio é de que a sanção jurídica, ao contrário de outros tipos de sanção social, não consiste ela mesma no uso da força, mas sim em uma obrigação secundária, que aparece com o descumprimento da obrigação primária e que passa a ser garantida pela ameaça do uso da força organizada ou, em último caso, pela execução de um ato de violência institucionalizada. Consistindo a sanção naquela obrigação de caráter secundário, derivado, pode ser ela tanto negativa quanto positiva - esta suscita no destinatário uma pretensão ao cumprimento (à entrega do "prêmio"), que é ela sim protegida pelo recurso potencial à força pública (BOBBIO, 2007, p. 28-29).

Essa ação indireta do Estado, paralela ao incremento de normas de conduta (com a peculiaridade do relevo dado à função promocional), é associada ao aumento do aparato burocrático pelo crescimento das normas de organização. De um lado, tem-se a atuação indutora do Estado; de outro, sua ação direta. O direito, antes reduzido a técnica de tutela e garantia, proteção e repressão, limitação das esferas de liberdade, é agora visto também como técnica de encorajamento, promoção, indução, empoderamento. Se um ordenamento de função repressiva pode implementá-la em diferentes graus - tornando a ação indesejada impossível, difícil ou apenas desvantajosa, a estrutura jurídica de função promocional igualmente pode lançar mão de estímulos de diferente intensidade - de modo a tornar a conduta necessária, fácil ou apenas vantajosa (BOBBIO, 2007, p. 1016). Tanto a função repressiva quanto a promocional podem ser implementadas de modo direto ou indireto. No caso de medidas positivas, a atuação indireta dos órgãos públicos está relacionada ao incentivo criado pela promessa de recompensa, enquanto a atuação direta consiste em tornar necessária a conduta requerida. Por conseguinte, em se tratando de medidas negativas, a atuação indireta do Estado se apresenta pelo aparato capaz de impor retribuição ou reparação, enquanto a atuação direta consiste em tornar impossível o comportamento indesejado (BOBBIO, 2007, p. 31). Em todos os casos de atuação indireta do Estado tem-se em vista uma atuação persuasiva do direito: atuar conforme o direito

Essa concepção de sanção institucionalizada garantida pelo Estado como monopólio da violência legítima ressoa aspectos tanto de Kelsen (2006, p. 35-40) quanto de Weber (2009, p. 525-529). 
pode ser mais ou menos custoso e o condicionamento das expectativas sobre os custos e benefícios é que torna o direito um instrumento de regulação graduada de incentivos e desincentivos a condutas. Daqui surge mais uma distinção: aquela entre incentivos (estímulos ao exercício de certa atividade) e prêmios (voltados a retribuir uma atividade já realizada) (BOBBIO, 2007, p. 72).

Postulação correlata de Bobbio trata da passagem de um controle social fundado em normas providas de sanção (positiva ou negativa) para uma direção social fundada sobretudo em normas técnicas. Dentre as normas técnicas, distingue as normas instrumentais, que se focam nos meios necessários para a obtenção de certos fins, e as normas diretivas, estas se voltando à indicação de fins. A tendência de crescimento das normas técnicas é associada, no diagnóstico de Bobbio (2007, p. 44-45 e 79), especialmente àqueles Estados em que a planificação econômica assume grandes proporções - seria o caso, à época (anos de 1960), dos países socialistas, nos quais haveria uma tendência a compreender a ciência jurídica como parte de uma ciência do direcionamento social (aproximada à cibernética). Assim, a ideia, que remonta a Jhering, de que as sanções positivas - a busca de vantagens - são praticamente irrelevantes para o direito (estatal), recaindo no domínio econômico (privado), mostra-se falsa em termos de uma teoria geral do direito: trata-se de mais uma contingência, vinculada a determinada configuração de Estado. Quando o Estado passa a ter maior presença na economia, também o direito premial "invade" o direito público (BOBBIO, 2007, p. 64-71). De outro lado, é possível postular também uma função redistributiva do direito, pois o direito público não mais se reduz no século $\mathrm{XX}$ ao direito penal; tampouco a economia contém-se no âmbito do direito privado (BOBBIO, 2007, p. 95-98) - o direito administrativo, o constitucional e o econômico confirmam tal afirmação. ${ }^{5}$

Finalmente, um último ponto a se destacar a respeito da análise funcional do direito em Bobbio diz respeito à hipótese de "perda de função do direito", ou melhor, de amenização da relevância da função repressiva do direito (aquela que lhe foi tradicionalmente atribuída) tendo em vista meios de socialização informais e os meios de comunicação de massa. Bobbio nota que em uma sociedade em que os condicionamentos psicológicos já produzem um grande consenso social (em casos extremos, seja de uma sociedade livre, como a imaginada por Marx, seja de uma sociedade totalitária, como a imaginada por Orwell), a função repressiva do direito enquanto instrumento de coação diminui de importância (BOBBIO, 2007, p. 89-90).

A despeito dessas hipóteses ou de casos extremos de coesão social fortificada seja pela violência totalitária, seja "voluntariamente", o caso normal do direito é aquele

Sobre a emergência do ramo do direito econômico vinculada ao contexto do Estado social, ver Comparato (1965). 
no qual a crítica dos institutos jurídicos pode encontrar na análise de suas funções um campo fértil para o pensamento jurídico. A atividade do jurista transcende a interpretação dogmática e passa a abarcar a comparação entre as funções propugnadas em relação às realizadas.

\section{Alternativas a Bobbio}

O contraste de Bobbio com outros dois autores que transitaram entre a teoria do direito e as ciências sociais pode ilustrar oportunidades de reconfiguração das propostas e diagnósticos do pensador italiano acerca da análise funcional do direito.

Um primeiro contexto tem a ver com o pano de fundo da teoria de Bobbio o Estado social - que, desde a época de seu diagnóstico, sofreu acentuadas transformações, o que poderia vir a colocar em xeque as funções então vislumbradas. Em um segundo contexto, interno à teoria do direito, caberia perguntar tanto em que medida a análise funcional de fato complementa a análise estrutural do direito sem modificá-la quanto de que outras formas podemos vincular estrutura e função em uma visão do direito como campo especializado da reprodução da sociedade.

Sobre o primeiro contexto do pensamento de Bobbio a que se fez referência, o contexto externo, social de sua teoria: em que medida mudaram as funções do direito tendo em vista a transição histórica do cenário em que Bobbio descrevia como novidade a atuação do Estado social? Aqui o motivo central é o decaimento relativo do Estado social, sobretudo desde os anos de 1970 e 80. Uma dinâmica de mundialização acelerada desde então coloca em xeque a função do direito (tal como identificada por Bobbio no contexto do Estado social de metade do século XX), assim como - para negar a tese de Bobbio sua estrutura.

Em primeiro lugar, vale lembrar a observação de Delmas-Marty sobre "hierarquias invertidas", inversão esta que já se iniciaria pelo fato de o conteúdo de uma norma superior não ser absolutamente determinado, mas sim preenchido pela norma inferior (que elegeu uma das alternativas de desdobramento possíveis a partir da norma superior) - assim, a norma inferior seria, ao menos em termos materiais, tão determinante à norma supraordenada quando esta em relação à infraordenada. Tal processo de inversão da hierarquia aconteceria mesmo na decisão judicial, na qual "uma indeterminação da norma" geral e abstrata "remete ao nível inferior o poder de determinar esta" (DELMASMARTY, 2004, p. 105). Kelsen busca contornar tal dinâmica paradoxal pela hierarquização linear e puramente formal entre normas inferiores que buscam seu fundamento de validade em normas superiores.

Mas, de outro lado, a própria estrutura escalonada da ordem jurídica é contrastável com a ideia de "hierarquias entrelaçadas" ou "enredadas", de Douglas 
Hofstadter. A partir dela, Delmas-Marty procede a uma crítica da noção kelseniana monista de estrutura escalonada do ordenamento jurídico (KELSEN, 2006, p. 215-238), na qual a hierarquia fundaria em uma só direção a validade de uma norma - exclusivamente com base na norma superior. No lugar da "hierarquia contínua e linear" simbolizada pela "pirâmide" das normas, "aparecem hierarquias descontínuas, como outras tantas pirâmides inacabadas, e hierarquias enredadas que formam 'anéis estranhos', retomando a imagem de Hofstadter" (DELMAS-MARTY, 2004, p. 87). Entre ordens jurídicas diversas, a autora visualiza relações de "hierarquias descontínuas e pirâmides inacabadas", interrupções de cadeias normativas e "coexistência de cortes supremas autônomas e não hierarquizadas entre si" (e.g., o Tribunal de Justiça das Comunidades Europeias e a Corte Europeia dos Direitos Humanos); de fato: há uma "interrupção quase total entre o direito da Comunidade Europeia e o da Convenção Europeia dos Direitos do Homem", enquanto que "[d]o direito interno aos direitos europeus, existe uma hierarquia e a norma europeia prevalece sobre a lei interna" (DELMAS-MARTY, 2004, p. 88). Por fim, há o enredamento entre ordens normativas que constroem "anéis estranhos" articuladores de uma alternatividade entre hierarquias:

a imagem do anel introduz a ideia de uma interação que não acarreta forçosamente o desaparecimento de todas as hierarquias, mas, antes, o enredamento delas e, por isso, o aparecimento de novos modos de geração do direito. Modos novos e diferentes uns dos outros conforme o enredamento ocorra entre sistemas autônomos e não hierarquizados, que criam hierarquias "alternativas" que estabelecem certa continuidade no ponto em que o processo normativo estava interrompido, ou se desenvolve a partir de sistemas já hierarquizados, ou parcialmente hierarquizados, tendo o efeito de inverter os níveis normativos ao fazer o nível inferior participar da determinação das normas de nível superior e favorecendo assim o aparecimento de hierarquias "invertidas". [...] Daí a análise proposta aqui em termos de hierarquias "alternativas", que talvez evoque mais o jogo das referências cruzadas que se observam de um sistema para outro. Referências que marcam alternativamente a primazia de um, e depois do outro, graças ao instrumento privilegiado de troca interativa constituído pelos princípios gerais do direito inclassificáveis na hierarquia piramidal clássica, mas também facilita o transporte das mensagens que ligam entre si sistemas aparentemente autônomos. (DELMAS-MARTY, 2004, p. 98-99).

Em relação ao cenário de Bobbio, de um lado, a tendência a uma relativa "reprivatização" ou liberalização do direito concorre com as próprias vicissitudes do funcionamento dos mecanismos estatais de compensação e estímulo ao funcionamento da 
economia. Aqui, a própria forma de programação decisória do direito vem a ser alterada, por meio de normatizações técnicas, procedimentos autorregulados e expectativas alinhadas aos tempos e demandas da economia, da ciência, com desacoplamento maior ou menor da dinâmica decisória da política estatal democrática; trata-se de regimes de regulação e governança altamente especializados e que "cognitivizam" o direito, moldando-o segundo planos de investimento, projetos de pesquisa e desenvolvimento e outras considerações extrajurídicas, pondo em xeque o vínculo constitucional entre direito e estado (vale lembrar, também um dos pilares da visão kelseniana da ordem jurídica) (AMATO, 2014, p. 189-245).

De outro lado, a progressão da dinâmica da mundialização parece ter conduzido a um sistema jurídico global programado por variadas ordens, com diferentes âmbitos de vigência (espacial, temporal, material e pessoal), como ordens nacionais, internacionais e supranacionais (e.g. os regimes universais e regionais de direitos humanos, o direito do comércio internacional, o direito comunitário europeu), assim como um direito corporativo setorial e direitos autóctones (AMATO, 2014, p. 263-275).

Para iluminar o segundo contexto do pensamento de Bobbio, seu contexto interno, sua posição teórica, a hipótese é de que visões alternativas sobre as estruturas jurídicas parecem indicar que uma abordagem funcional do direito não implica necessariamente aceitar a visão kelseniana da abordagem estrutural, como defendeu Bobbio. Proponho aqui contrastar a teorização bobbiana (como mencionado, trabalhada entre 1969 e 1976) com os construtos de outros dois autores que transitaram entre a teoria do direito e a teoria social nas décadas seguintes. O primeiro deles é o alemão Niklas Luhmann, cujos principais escritos jurídicos são os livros Sociologia do direito, de 1972, e $O$ direito da sociedade, de 1993. O outro autor é Roberto Mangabeira Unger, que, além de $O$ direito na sociedade moderna, de 1976, e de outras obras em que imerge o direito na teoria social, escreveu o manifesto d'O Movimento de Estudos Críticos do Direito (originalmente palestra de 1982, publicada como artigo em 1983, como livro em 1986 e em re-edição ampliada em 2015) e $O$ direito e o futuro da democracia, de 1996. A proposta não é aceitar totalmente nenhuma das propostas desses autores (Bobbio, Luhmann ou Unger), mas sim tomá-las como ponto de partida para outra visão do direito: um construtivismo jurídico de enfoque sistêmico e institucional (AMATO, 2017a).

Partamos para a questão: um enfoque funcional do direito deixa intacta a visão canônica, kelseniana, de suas estruturas? A relação de supra e infra-ordenação meramente formal entre normas jurídicas, que retiram sua validade das formas e procedimentos definidos por outras normas jurídicas, conduziu à estrutura escalonada (Stufenbau) teorizada por Merkl e Kelsen. Tal hierarquia formal de validade das normas deixa em aberto a definição do conteúdo para além das atribuições de competência. 
Pretender, em perspectiva dita "pós-positivista", simplesmente diferenciar "tipos" de normas (regras, princípios, postulados) e manter intacta a visão do ordenamento normativo é entendimento sincrético desautorizado, uma solução de compromisso com o positivismo analítico rejeitada pelos próprios teóricos defensores da idealização do direito por referência a políticas e princípios tendentes a construírem teorias morais abrangentes. Saindo dos cânones do positivismo normativista, pretender que o direito seja um conjunto de elementos individualizáveis e contáveis chamados normas, princípios ou regras jurídicas, diferenciáveis de outros tipos de normas (morais, costumeiras, técnicas), parece "uma ficção escolástica", como qualificou Dworkin (2006, p. 4).

Mesmo críticos dessa corrente de idealização moralizante do direito, Luhmann e Unger apresentaram concepções sobre a estrutura do direito que tampouco se confundem com a visão "piramidal” do ordenamento jurídico teorizada por Kelsen e divulgada por Bobbio. Luhmann (2014) identificava o conceito de norma ao de expectativa normativa, discernindo o campo do direito não pela delimitação de um conjunto de normas, mas pela função que o direito desempenharia com relação às expectativas contrafáticas espraiadas por toda a sociedade e seus sistemas sociais parciais: a função de generalização congruente dessas expectativas - de sua simbolização, programação decisória e sustentação procedimental. Mais tarde, Luhmann (2004) frisou que o direito se diferencia (da moral, da política, da economia, da educação, da religião, da ciência) por sua função e por suas operações (a comunicação sobre o lícito e o ilícito), não por suas estruturas (as normas); aí ofereceu uma autodescrição do sistema jurídico não como conjunto de normas, mas sim como cadeia autorreferencial, circular, de comunicações sobre o "código" (em sentido cibernético, não linguístico) lícito/ilícito. Luhmann (2004, cap. 3) então volta a definir o direito pelo isolamento de uma função específica (esta de generalizar congruentemente expectativas normativas), em vez de distinguir e listar diferentes "funções" ou, conforme o contexto histórico, descrever os diferentes "usos" ou “orientações” do direito (ver especialmente LUHMANN, 2004, p. 148, nota 17).

Por sua vez, Unger (2015, parte I) buscou se contrapor às correntes críticas do direito que o veriam como um fenômeno "amorfo", sem estruturas próprias, suscetível de justificar qualquer interpretação autoritativa dos textos normativos. Assim, vislumbrou o direito como conjunto de soluções dominantes e soluções desviantes para a organização da sociedade, da economia, da política, entendendo que esse padrão se repete ao longo de todo o corpo do direito e em cada um de seus ramos.

Essa discussão nos conduz à provocação: como podemos definir função e estrutura e analisá-las de forma diferente da proposta por Bobbio? Um ponto de partida é a ideia da sociologia clássica, que concebia o direito como estrutura da sociedade. Essa ideia é retomada tanto por Luhmann (2014) quanto por Unger (2017; 2013). Mas então, 
precisaríamos articulá-la a seu complemento: a ideia de estruturas internas do direito. Esse é o ponto de partida de um construtivismo jurídico (AMATO, 2017a).

Luhmann dá três pistas para tal projeto. A primeira é a concepção de que a autorreferência dos sistemas, seu fechamento operacional, tem como contraparte indispensável a ideia de estruturas de cada sistema (LUHMANN, 1995, p. 281-282). A segunda pista é a definição luhmanniana de instituições como "expectativas de comportamento temporal, objetual e socialmente generalizadas e [que] como tais formam a estrutura dos sistemas sociais" (LUHMANN, 2010, p. 86). A terceira é o que se poderia chamar de "morfologia" institucional dos sistemas sociais, apresentada quando Luhmann (2004, cap. 7) trata da distinção entre centro e periferia dos sistemas sociais: por exemplo, os poderes políticos e os privados, a legislação e os contratos estão na periferia do direito; seu centro são as cortes, as sentenças.

A partir da definição de instituições como estruturas internas dos sistemas sociais, podemos dar novo uso conceitual a uma longa tradição jurídica (AMATO, 2017b): Santi Romano definiu a instituição como ordenamento jurídico, identificando-a com a estrutura interna das organizações; Weber apresentou o estado e as entidades de direito público como instituições, em relação com uma pluralidade de ordens jurídicas; Hauriou conceituou as instituições como eixo durável da vida social, em oposição às definições do direito pela vontade e pelas pessoas (subjetivismo) ou pela norma jurídica (objetivismo). Com a redefinição proposta da perspectiva institucional, cedo apresentada e logo abandonada pelo próprio Luhmann, podemos adentrar a configuração interna dos sistemas sociais e perguntar acerca de sua representação e detalhamento jurídico, estabelecendo regime de cooperação entre a sociologia e o pensamento jurídico.

Nesse sentido é que Unger esboça um método para a análise jurídica. Retomando o institucionalismo jurídico francês (UNGER, 2001, p. 633), propõe, para as ciências sociais em geral (UNGER, 2001) e para o direito e a economia política em particular (UNGER, 2004), concentrarem-se na "imaginação institucional". Unger (2004) apresenta a ideia de "imaginação institucional" como tarefa de análise do direito e proposição de reformas jurídicas a partir do mapeamento e da crítica das formas alternativas de organização das diversas áreas da sociedade, formas estas representadas, justificadas e esquadrinhadas no corpo do direito e no discurso doutrinário. Seu conceito de instituição é de "[u]m conjunto de regras e crenças que formata um aglomerado de práticas informado pela concepção de como as pessoas, em certo domínio da vida social, podem e devem lidar umas com as outras" (UNGER, 2013, p. 14).

Pode-se dizer que tal "imaginação institucional" seria uma tarefa para o papel que Bobbio (2007, p. 37-38, 92-93) definia como aquele do "jurista pesquisador". Porém se note que, aqui, a "neutralidade axiológica" da análise funcional, que Bobbio disse ser possível, é matizada, pois tal terreno já se avizinha do debate ideológico político. 
Mas também se deixa “contaminar" pela discussão econômica, educacional, sanitária, conforme o setor do direito e da sociedade que se tem em vista. Na linha da tarefa de “imaginação institucional” propugnada por Unger (2004, p. 159-165), o que se pratica é o mapeamento, a imaginação e o desenho de modos alternativos de estruturação jurídica para o alcance de determinada funcionalidade.

No entanto, teríamos que distinguir aqui as estruturas jurídicas e as semânticas jurídicas (AMATO, 2017a, parte II). Aquilo de que a "abordagem estrutural" do positivismo analítico do século XX tratou foi principalmente a semântica jurídica: o repertório de normas, regras, sua ordenação. Essa é a tradicional ideia de sistema ou ordenamento jurídico. Quando passamos a conceber o sistema jurídico como sistema social, discernimos aquelas estruturas que são suas representações, teorias, materiais interpretativos - normas, doutrina, jurisprudência, o corpo do direito -, e a elas podemos chamar de semântica. De outro lado, estão as estruturas institucionais: formas de organização judicial, de configuração de direitos subjetivos, de modelagem de procedimentos decisórios. As estruturas institucionais (ou instituições) são representadas pelas estruturas semânticas (ou semânticas), mas a discussão sobre semântica jurídica (programação decisória, interpretação, argumentação, justificação) torna-se apenas parte de um enfoque sobre as formas institucionais do direito, da economia, da política. Ao pensamento jurídico cabe refletir sobre a "agregação" de normas em instituições e a "decomposição" de instituições em normas, discernindo as alternativas em cada percurso e em vista das funcionalidades desejadas.

Um ponto de partida para detalhar tais formas institucionais seria a institucionalidade interna dos sistemas sociais parciais (direito, política, economia, saúde, educação, arte, ciência) "mapeada" com alto grau de generalidade e abstração pela teoria dos sistemas autorreferenciais. Então poderíamos discernir formas variadas de estruturação das organizações centrais e periféricas dos sistemas, mas também de seus "ambientes internos" (o mercado, a opinião pública, a personalidade jurídica) e dos vínculos procedimentais entre "esferas públicas" e "esferas organizadas" (como o voto e a participação política, as variadas formas de ação judicial, os mecanismos de crédito/ dívida e poupança/investimento).

Porém, teríamos que assumir a hipótese de que o discurso jurídico mimetiza essa própria "morfologia" do direito. Ao lado das teorias voltadas para a interpretação judicial e a solução de controvérsias no centro de controle de consistência do direito - as cortes -, haveria uma dogmática ou doutrina potencializada pela discussão normativa e pela pesquisa empírica. Ela estaria direcionada à periferia de inovação do direito, informando legisladores, administradores e ordenadores privados, voltando-se à criação e à transformação do direito, com impacto apenas mediato sobre a interpretação do direito posto realizada por juízes. Seu escopo, portanto, não se confunde com o de uma 
interpretação jurídica preocupada com a "função social", com a atribuição de propósitos a normas dadas. É em primeiro lugar um método para a reforma do direito (AMATO, 2017a, parte III).

Seu praticante, o "jurista pesquisador", haveria de investigar e propor arranjos contratuais, reformas legislativas, desenhos de transações e procedimentos. Não produziria uma sociologia jurídica pura, uma descrição à distância do sistema jurídico como conjunto de semânticas e estruturas, como ordem diferenciada de comunicações. Embora possam mobilizar tal conhecimento e outros tantos, tal jurista e tal tarefa pragmática seriam eles mesmos um elo de "irritação" da inovação jurídica, da construção do próprio direito. Essa "imaginação institucional" mixa então a semântica jurídica - a visão ordenada e justificativa dada pela doutrina, o conhecimento das normas - com a heterorreferência a outros sistemas sociais. Terá que trabalhar com o instrumental analítico da economia se quiser propor mudanças no direito econômico; haverá de considerar questões pedagógicas na reforma do direito da educação; considerará os problemas da mobilização política quando tratar de alterações nos arranjos constitucionais.

Considerações Finais

Bobbio (1990, p. 177-178, nota 3) rejeitou que a visão dogmática do direito constituísse uma técnica, contraposta à ciência do direito concebida em termos jusnaturalistas, psicológicos ou sociológicos. Isso representaria um regime de dupla verdade: o que é verdade para o jurista prático ou o estudioso de um ramo dogmático do direito poderia não ser verdade em termos da "ciência jurídica". Criticando tal construção, Bobbio (1990, p. 184-193) identificou a ciência do direito à tarefa dos juristas de interpretação: de purificação da linguagem das normas, integração de lacunas e sistematização do material dado para a decisão.

A partir da mesma rejeição a um regime de dupla verdade, Bobbio (1990, p. 73-90 e 91-101) fez distinguir a filosofia do direito em relação à teoria geral do direito. Àquela atribuiu a tarefa de pesquisar as diferentes concepções do valor da justiça; o problema filosófico estrito seria relacionado aos valores, enquanto que à ciência do direito importaria a questão da validade formal. Já à teoria geral do direito atribuiu um caráter científico e formal - formal não no sentido kantiano (de delimitação a priori de uma esfera ideal das possibilidades, distinta da esfera empírica dos fatos), mas no sentido de ter por objeto privilegiado a norma jurídica e sua integração sistemática no ordenamento jurídico. Não sendo uma filosofia que constrói conhecimentos a priori, independentes da experiência, a teoria geral do direito é ciência e trata da natureza, constituição, funcionamento e extinção da norma jurídica, das fontes do direito, da estrutura típica da norma (antecedente e consequente, sujeito passivo e ativo, prestação). Trata de responder, 
enfim à pergunta: como está formado o ordenamento jurídico? Aqui está a gênese da concepção de teoria do direito como uma teoria formal, como uma análise estrutural do direito. A diferença entre a teoria geral e a dogmática jurídica - ambas matérias científicas, e não filosóficas - estaria apenas em que uma trata das formas, da estrutura (norma e ordenamento jurídico), e a outra (os ramos dogmáticos) volta-se aos conteúdos normatizados.

Na concepção de ciência jurídica de Bobbio é que se encontram as raízes de seu debate sobre estrutura e função. Se inicialmente Bobbio identificava a teoria do direito à análise puramente estrutural de norma e ordenamento jurídico, seu esforço posterior para integrar a análise funcional também ao campo da teoria do direito (ainda que em intercâmbio com a sociologia jurídica) é coerente com o percurso teórico global do autor. Mais uma vez o que se encontra aqui é uma rejeição ao regime da "dupla verdade" e ao isolamento dogmático do jurista. Em vez de distanciar a análise funcional típica dos sociólogos da análise estrutural com a qual se acostumaram os juristas do século XX, Bobbio caminha na interface. E aqui caberia evocar o diagnóstico de Weber em 1904:

Toda pesquisa nas ciências culturais em uma era de especialização, uma vez que sendo orientada a dada matéria por meio de determinadas colocações dos problemas e com seus princípios metodológicos estabelecidos, verá na elaboração desse assunto um fim em si mesmo. Deixará de considerar o valor dos fatos individuais em termos de suas relações com ideias últimas de valor. E mesmo perderá a consciência de seu último enraizamento em ideias de valor em geral. Tudo bem que seja assim. Mas então chega o momento em que a atmosfera muda. O significado dos pontos de vista irrefletidamente utilizados torna-se incerto e o caminho foi perdido no crepúsculo. A luz dos grandes problemas culturais se esvai. Então a ciência também se prepara para mudar sua perspectiva e seu aparato analítico e para ver o curso dos eventos das alturas do pensamento. (WEBER, 1949, p. 112).

Em Bobbio, um velho dilema ganha novos encaminhamentos. Reconhecendo o caráter convencional da distinção entre as disciplinas dogmáticas e as "filosóficas" no estudo do direito, Bobbio se indagava se era preferível a especialização (com a fragmentação de disciplinas "fundamentais" em filosofia, sociologia, antropologia e teoria do direito) ou a unidade, sob o rótulo genérico de "filosofia do direito". A unidade, acreditava, ajudaria a "romper os diques que mantêm as disciplinas jurídicas tradicionais no reservatório artificial de um sistema positivo" (BOBBIO, 1990, p. 101). Anos depois, ensaiaria outra solução: incluir na teoria do direito, ao lado da análise estrutural, a perspectiva funcional, tornando tal teoria apta a lidar com as mudanças sociais, políticas e econômicas de sua época. 
Partindo da ansiedade weberiana que desde cedo (UNGER, 1968, p. 97-98) informou sua empreitada de renovação da teoria social e jurídica, Unger (2007, p. 125 e 234) veio a concluir que a filosofia pode servir como "antídoto" parcial à "superstição", para "informar nossas práticas de autoinvenção individual e coletiva" e, antes disso, para "sacudir as disciplinas como organizadas e distinguidas pela organização profissional do conhecimento especializado". Assim, se não é possível observar as formas de organização social de um ponto de vista de Deus, imparcial e imune às preconcepções do tempo e lugar em que vivemos, podemos sim procurar por arranjos institucionais que nos habilitem a não confundir "o local pelo universal" e a compreender os constrangimentos estruturais sem tomá-los como destino inalterável. Aí a especialização universitária das disciplinas, com métodos canônicos associados a cada matéria, teria que ser confrontada pela "imaginação", isto é, pela abordagem incongruente das mesmas matérias de pontos de vista contrastantes.

Nesse sentido, podemos dizer que observar a juridicidade com interesse em sua transformação - e não diretamente em sua reprodução interpretativa - implica fundir as barreiras disciplinares entre dogmática jurídica, sociologia, filosofia e teoria do direito. Submetendo-as a pressão e calor, ajudamos a posicionar o direito e a estruturação jurídica de todos os âmbitos sociais do ponto de vista de um insight no que eles podem vir a ser, adensando a própria compreensão do sentido de como eles hoje são. Segundo a alternativa construtivista proposta em desdobramento da contribuição de Bobbio e em diálogo com Luhmann e com Unger, construir um conhecimento do direito como estrutura da sociedade, mas também um conhecimento da especificidade funcional do próprio sistema jurídico, ajuda a compreender como o direito constrói a sociedade ao construir a si mesmo.

São Paulo,17 de maio de 2017.

\section{Referências}

AMATO, Lucas Fucci. As formas da sociologia do direito: uma redescrição luhmanniana do debate centenário entre Kelsen e Ehrlich. Nomos: Revista do Programa de Pós-Graduação em Direito da $U F C$, Fortaleza, v. 35, n. 2, p. 227-254, 2015.

. Constitucionalização corporativa: direitos humanos fundamentais, economia e empresa. Curitiba: Juruá, 2014.

. Construtivismo jurídico: teoria no direito. Curitiba: Juruá, 2017 a.

Institucionalismo, pluralismo, corporativismo: 100 anos de "O ordenamento jurídico", de

Santi Romano. Quaestio Iuris, Rio de Janeiro, v. 10, n. 4, p. 2.656-2.677, $2017 \mathrm{~b}$. 
BOBBIO, Norberto. Contribución a la teoría del derecho. Tradução de Alfonso Ruiz Miguel. Madrid: Debate, 1990.

. Da estrutura à função: novos estudos de teoria do direito. Tradução de Daniela Beccaccia Versiani. Barueri: Manole, 2007.

. Direito e poder. Tradução de Nilson Moulin. São Paulo: Editora Unesp, 2008.

- Ensaios sobre Gramsci e o conceito de sociedade civil. Tradução de Marco Aurélio Nogueira e Carlos Nelson Coutinho. São Paulo: Paz e Terra, 1999.

. Estado, governo, sociedade: para uma teoria geral da política. Tradução de Marco Aurélio Nogueira. Rio de Janeiro: Paz e Terra, 2010b.

. O conceito de sociedade civil. Tradução de Carlos Nelson Coutinho. Rio de Janeiro: Graal, 1982. 2010a.

. Teoria geral do direito. Tradução de Denise Agostinetti. 3. ed. São Paulo: Martins Fontes, ; BOVERO, Michelangelo. Sociedade e Estado na filosofia política moderna. Tradução de Carlos Nelson Coutinho. 3. ed. São Paulo: Brasiliense, 1991.

COHEN, Felix Solomon. Transcendental nonsense and the functional approach. Columbia Law Review, New York, v. 35, n. 6, p. 810-849, Jun. 1935.

COMPARATO, Fábio Konder. O indispensável direito econômico. Revista dos Tribunais, São Paulo, v. 54, n. 353, p. 14-26, mar. 1965.

DE GIORGI, Raffaele. Ciencia del derecho y legitimación. Ciudad de México: Universidad Iberoamericana, 1998.

DELMAS-MARTY, Mireille. Por um direito comum. Tradução de Maria Ermantina de Almeida Prado Galvão. São Paulo: Martins Fontes, 2004.

DWORKIN, Ronald. Justice in robes. Cambridge, MA: Belknap Press, 2006.

FEBBRAJO, Alberto (Org.). Eugen Ehrlich, Hans Kelsen, Max Weber. Verso un concetto sociologico di diritto. Milano: Giuffrè, 2010. (Serie sociologico-giuridica).

HART, Herbert L. A. O conceito de direito. Tradução de A. Ribeiro Mendes. 5. ed. Lisboa: Fundação Calouste Gulbenkian, 2007.

KELSEN, Hans. Essência e valor da democracia. In: . A democracia. 2. ed. Tradução de Ivone Castilho Benedetti, Jefferson Luiz Camargo, Marcelo Brandão Cipolla e Vera Barkow. 2. ed. São Paulo: Martins Fontes, 2000b. p. 23-107.

. On the borders between legal and sociological method. In: JACOBSON, Arthur J.; SCHLINK, Bernhard (Ed.). Weimar. A jurisprudence of crisis. Translated by Belinda Cooper et al. Berkeley: University of California Press, 2000a. p. 57-63. 
KELSEN, Hans. Teoria geral do direito e do Estado. Tradução de Luís Carlos Borges. 3. ed. São Paulo: Martins Fontes, 2000c.

. Teoria pura do direito. Tradução de João Baptista Machado. 7. ed. São Paulo: Martins Fontes, 2006.

LUHMANN, Niklas. A sociological theory of law. Tradução de Elizabeth King-Utz e Martin Albrow. 2. ed. New York: Routledge, 2014.

. Law as a social system. Tradução de Klaus A. Ziegert. Oxford: Oxford University Press, 2004.

. Los derechos fundamentales como institución: aportación a la sociología política. Tradução de Javier Torres Nafarrate. México: Universidad Iberoamericana, 2010.

. Social systems. Tradução de John Bednarz, Jr. e Dirk Baecker. Stanford: Stanford University Press, 1995.

MICHELON JR., Cláudio Fortunato. Aceitação e objetividade: uma comparação entre as teses de Hart e do positivismo precedente sobre a linguagem e o conhecimento do direito. São Paulo: Revista dos Tribunais, 2004.

NONET, Philippe; SELZNICK, Philip. Law and society in transition: toward responsive law. New Brunswick; London: Transaction Publishers, 2001.

RADCLIFFE-BROWN, Alfred Reginald. Estrutura e função na sociedade primitiva. Tradução de Nathanael C. Caixeiro. Petrópolis: Vozes, 1973.

RENNER, Karl. The institutions of private law and their social functions. Tradução de Agnes Schwarzschild. London: Routledge \& K. Paul, 1949.

ROMANO, Santi. O ordenamento jurídico. Tradução de Arno Dal Ri Júnior. Florianópolis: Fundação Boiteux, 2008.

UNGER, Roberto Mangabeira. False necessity: anti-necessitarian social theory in the service of radical democracy. 2. ed. London: Verso, 2001.

. O direito e o futuro da democracia. Tradução de Caio Farah Rodriguez e Marcio Soares Grandchamp, com consultoria do autor. São Paulo: Boitempo, 2004.

. O estruturalismo e o futuro das ciências culturais. Tempo brasileiro, Rio de Janeiro, v. 1516, p. 97-102, 1968.

. O movimento de estudos críticos do direito: outro tempo, tarefa maior. Tradução de Lucas Fucci Amato. Belo Horizonte: Casa do Direito, 2017.

2007.

. The self awakened: pragmatism unbound. Cambridge, MA: Harvard University Press, 
UNGER, Roberto Mangabeira. The universal history of legal thought. 2013. Disponível em: <http:// www.robertounger.com/en/wp-content/uploads/2017/01/the-universal-history-of-legal-thought. pdf>. Acesso em: 3 jul. 2015.

WEBER, Max. Economia e sociedade: fundamentos da sociologia compreensiva. Tradução de Regis Barbosa e Karen Elsabe Barbosa. Brasília: Editora UnB, 2009. v. 2.

. "Objectivity" in social science and social policy. In: The methodology of the social sciences. Tradução e edição de Edward A. Shils e Henry A. Finch. Glencoe: The Free Press, 1949. p. 49-112. 